\title{
ACRL 1980/81 Budget
}

ACRL Summary Budgets

\begin{tabular}{|c|c|c|}
\hline \multicolumn{3}{|c|}{ ACRL } \\
\hline & $1979 / 80$ & $1980 / 81$ \\
\hline Revenue & $\$ 268,929$ & $\$ 333,881$ \\
\hline \multirow[t]{2}{*}{ Expense } & 365,134 & 391,922 \\
\hline & $(96,205)$ & $(58,041)$ \\
\hline Reserve & 110,912 & 74,952 \\
\hline \multirow[t]{2}{*}{ Balance } & $\$ 14,707$ & $\$ 16,911$ \\
\hline & Choice & \\
\hline \multirow{3}{*}{$\begin{array}{l}\text { Revenue } \\
\text { Expense }\end{array}$} & $\$ 656,624$ & $\$ 708,814$ \\
\hline & 677,123 & 698,749 \\
\hline & $(20,499)$ & 10,065 \\
\hline \multirow[t]{2}{*}{ Reserve } & 56,670 & 36,171 \\
\hline & $\$ 36,171$ & $\$ 46,236$ \\
\hline
\end{tabular}

*Estimate provided by ALA Controller

Figures in parentheses are negative amounts

\section{Highlights}

At the annual meeting in New York, the ACRL Board of Directors adopted the 1980/81 ACRL budget. Highlights of the budget include:

- An increase in revenues generated by inhouse publishing (up from $\$ 1,600$ to $\$ 7,100$ ).

- The addition of a revenue line for continuing education activities $(\$ 4,000)$ to reflect the Association's return on its investment in staffing this area.

- An increase in revenues for College d Research Libraries (up from $\$ 76,772$ to $\$ 97,550$ ). Half of this increase is in the area of subscriptions and half in display advertising.

- An increase in revenues for CtRL News (up from $\$ 64,183$ to $\$ 78,169$ ). Most of this increase results from increased staff efforts in classified advertising, including late job listings.

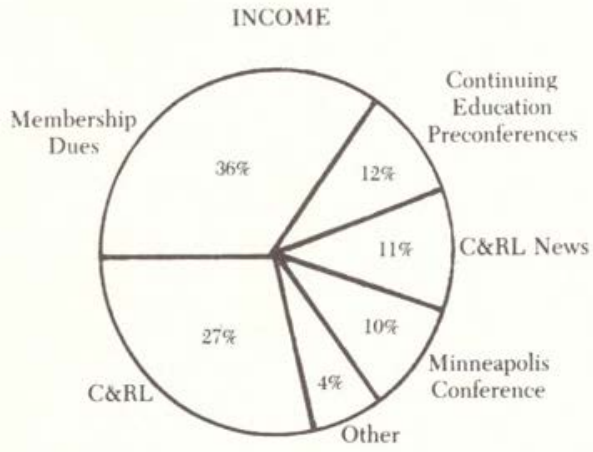

- The allocation of $\$ 6,099$ to ACRL chapter support.

- The approval of budgets for three perconferences at the San Francisco 1981 ALA meeting. These preconferences will be sponsored by BIS, CJCLS, and RBMS.

- The approval of the budget for a continuing education course on working with archives to be held in advance of the 1981 San Francisco conference and the 1981 ACRL National Conference in Minneapolis.

- The addition of a part-time program officer for bibliographic instruction and support for that position, if the ACRL balance at August 31, 1980, is greater than $\$ 90,000$.

- The addition of a half-time editorial assistant for the editor of College \& Research Libraries.

- The implementation of an ACRL JOBLINE for listing academic library positions beginning September 1, 1980. (The telephone number of the JOBLINE is (312) 944-6795).

\section{Income and Expenditures}

The pie chart below shows the major projected sources of revenue and expenditures for ACRL, excluding Choice, in 1980/81.

A compilation indicating where ACRL funds (including staff time) are specifically derived from and expended is shown on the next page. Comparisons with the previous year are also shown.

This compilation reflects ACRL's move toward program budgeting. It is expected that the next year's budget will be further refined so that preconferences will be shown as section activities rather than being included with continuing education activities.

The increases in income for C\&RL News have been projected conservatively since a number of changes will be made during 1980/81. A new edi-

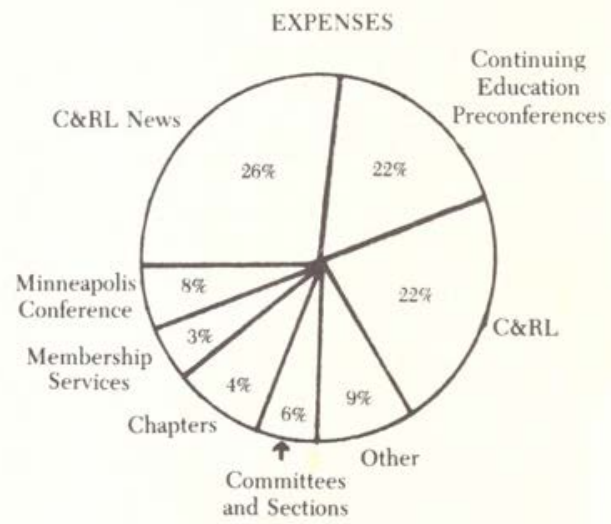


tor is joining the staff, the contract for the production of the News has been terminated with the ALA Central Production Unit and production responsibilities have been assumed by the Editor, a late job listing section has been added as a result of the greater control over scheduling, and an increased promotional effort is being made in display advertising and subscription sales. Results of these changes are already being seen as we move toward the end of the current fiscal year.

It can be seen that the proportion of the total revenues derived from membership dues is shrinking yearly (36.4 percent in 1980/81 compared with 43.2 percent in $1979 / 80$ ). Inflation has increased expenditures, while the ACRL dues rate has remained constant for the past six years. Additional sources of revenue must therefore be created. Ultimately a dues increase is inevitable.

The ALA Council took action in June to decrease student divisional membership dues from $\$ 15$ to $\$ 5$. This proposed decrease will have an unbudgeted impact on ACRL's membership income of slightly over $\$ 3,000$ if it is passed by the ALA membership.

The Budget and Finance Committee has been charged to look at the long-term financial needs of ACRL and to make recommendations to the ACRL Board of Directors.

\section{INCOME}

\section{Activity}

Membership

$C \mathcal{U} R L$

C¿RL News

CE Activities

Alloc. from Minn.

Published Materials

Alloc. from Choice

Contributions \& Gifts

TOTAL

Activity

CURL News

CE Activities

CERL

Minneapolis Conf.

Chapters

Membership Promo.

Committees

Sections

Advisory

Orders

*Choice

Fast Job Listing Serv.

Univ. Lib. Stat.

3rd Nat'l. Conf.

ACRL 100 Project

Outside Publishing

SCMAI

ARL/OMS/ALP

Discussion Groups

NPC

Accreditation Wkshop

White House Conf.

Equipment

Internship Project

TOTAL

$\begin{array}{r}\mathbf{1 9 7 9} / 80 \\ \$ 116,049 \\ 69,492 \\ 27,000 \\ 35,288 \\ 15,000 \\ 1,600 \\ 3,400 \\ 1,100 \\ \hline \$ 268,929\end{array}$

1980/81

$\$ 121,445$

88,814

37,448

39,585

33,143

7.100

5,246

1,100

$\$ 333,881$

\section{Difference}

\$ 5,396

19,322

10,488

4,297

18,143

5,500

1,846

\$ 64,992
$\%$ of $1979 / 80$

43.2

\section{8}

10.0

13.1

5.6

6

1.3

0.4
$\%$ of $1980 / 81$

36.4

26.6

11.2

11.9

9.9

2.1

1. 6

0.3

\section{Difference}

(6.8)

.8

1.2

(1.2)

4.3

1.5

.3

(0.1)

\section{EXPENDITURES}

\section{EXPENDITURES}

$\begin{array}{rr}\mathbf{1 9 8 0} / 81 & \text { Difference } \\ \$ 102,309 & \$ 13,748 \\ 85,473 & 21,385 \\ 85,441 & 11,278 \\ 33,143 & 18,143 \\ 15,905 & (750) \\ 13,680 & (8,143) \\ 12,486 & (3,438) \\ 10,013 & (3,198) \\ 7,126 & 273 \\ 6,002 & 20 \\ 4,217 & 2,109 \\ 4,039 & 374 \\ 3,639 & (6,085) \\ 2,388 & (286) \\ 1,786 & 372 \\ 1,636 & 1,320 \\ 1,236 & (80) \\ 915 & (39) \\ 428 & 7 \\ 60 & (17) \\ 0 & (12,170) \\ 0 & (5,075) \\ \text { N/Appl. } & - \\ 0 & (1,152) \\ \$ 391,922 & \end{array}$

$\%$ of 1979/80 $\%$ of $1979 / 80$ \$ 88,561 64,088

74,163

15,000

16,655

21,823

15,924

13,211

6,853

5,982

2,108

3,665

9.724

2,674

1,414

316

1,316

954

421

77

12,170

5,075

1,808

1,152

$\$ 365,134$

\section{0/81 Difference}

$\begin{array}{rrc}24.2 & 26.1 & 1.9 \\ 17.8 & 21.8 & 4.0 \\ 20.3 & 21.8 & 1.5 \\ 4.1 & 8.5 & 4.4 \\ 4.6 & 4.1 & (0.5) \\ 6.0 & 3.5 & (2.5) \\ 4.4 & 3.2 & (1.2) \\ 3.6 & 2.6 & (1.0) \\ 1.9 & 1.8 & (0.1) \\ 1.6 & 1.5 & (0.1) \\ 0.6 & 1.1 & 0.5 \\ 1.0 & 1.0 & 0 \\ 2.7 & 0.9 & (1.8) \\ 0.7 & 0.6 & (0.1) \\ 0.4 & 0.5 & 0.1 \\ 0.1 & 0.4 & 0.3 \\ 0.4 & 0.3 & (0.1) \\ 0.3 & 0.2 & (0.1) \\ 0.1 & 0.1 & 0 \\ 0.0 & 0.0 & 0 \\ 3.3 & 0 & (3.3) \\ 1.4 & 0 & (1.4) \\ 0.5 & \text { N/Appl. } & - \\ 0.3 & (0.3) & (0.3)\end{array}$

*This reflects the amount of unreimbursed ACRL staff costs spent on Choice and absorbed by the ACRL 303 budget. 


\section{An essential reference book for those who need to keep abreast of electrotechnology.}

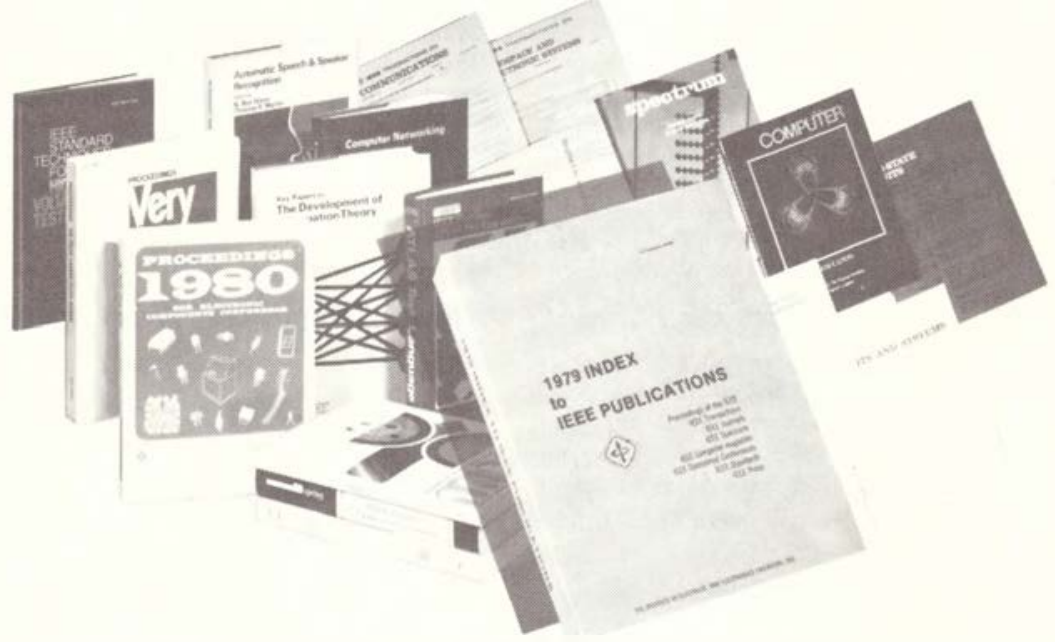

\section{IEEE Annual Combined Index}

For engineers and scientists whose duties require detailed awareness of the state of the art in electrotechnology, there is no substitute for our annual lndex.

In an easy-to-use single volume, the Index provides quick access to all IEEE-published papers, articles, and other communications covering every facet of electrical/ electronics science and engineering. Information is accessible both by subject and by author

Access $\mathbf{4 0 , 0 0 0}$ periodical pages. Electrical/electronics applications are now so pervasive that there are IEEE periodicals specializing in fields of interest that might surprise you: biomedicine ... geoscience... nuclear and plasma science pattern analysis ... oceanic engineering ... cybernetics.

These are the highly-cited, highimpact journals in their disciplines. There are now 45 such periodicals totaling over 40,000 pages annually.

Access 60,000 non-periodical pages. The Index also cites all papers pre- sented at over 100 major IEEEsponsored conferences covering every subject held worldwide during that year. In addition, the Index includes all new IEEE Standards. IEEE Press books, IEEE technical reports and miscellaneous IEEE publications. IEEE's massive book publishing program adds up to over 60,000 pages yearly.

Over 17,500 technical items. Over 120,000 entries.

The annual Index to IEEE Publications also contains several appendixes that provide useful bibliographic information on all indexed publications: periodicals ... special issues ... conference records and digests ... IEEE Standards and IEEE Press books. This is the information you will need in order to fully identily a complete publicaton or to order it from IEEE.

Our annual lndex is the only index that covers the totality of IEEE publishing - the world's largest source of new information in electrotechnology.
How to order the IEEE Index.

The IEEE annual combined Index is available in the fall of the year following the publication year. These paperbound indexes are now in stock

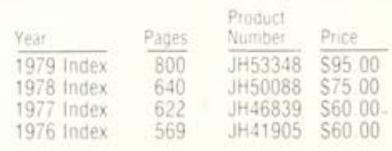

To order. please enter full title. product number and price. Make check payable to IEEE A \$2 00 handling charge is added to all non-prepaid orders of under $\$ 100$. New Jersey residents please adj $5 \%$ state sales tax. Mail your order to

IEEE Service Center. Publication Sales - Dept. D 445 Hoes Lane. Piscataway. NJ 03854 . U.S.A.

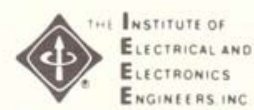

Serving 200.000 members and 14.000 libraries worldwide

IEEE. The world's leading source of new information in electrical and electronics science and engineering. 